\section{Tropical Journal of Ophthalmology and Otolaryngology}

2021 Volume 6 Number 1 January-February

\title{
Relationship between habits and precancerous lesions of the oral cavity - a clinicopathological study
}

\author{
Kumar Yadlapalli A. ${ }^{1}$, Santosh B. ${ }^{2 *}$, 5 K Reddy D. ${ }^{3}$, Veeranjaneyulu P. ${ }^{4}$, Lakshmi Snehitha M. ${ }^{5}$, \\ Priyanka P. 6
}

DOI: https://doi.org/10.17511/jooo.2021.i01.01

${ }^{1}$ Ajay Kumar Yadlapalli, Associate Professor, ${ }^{2 *}$ B Krishna Santosh, Associate Professor, ${ }^{3}$ Dwarampudi S K Reddy, Former Resident, ${ }^{4}$ Panda Veeranjaneyulu, Professor and Head, ${ }^{\mathbf{5}}$ Maroju Lakshmi Snehitha, Junior resident, $\mathbf{6}$ Pothula Priyanka, Junior Resident; All the authors are affiliated with the Department of ENT, GSL Medical College, Rajahmundry, Andhra Pradesh, India.

Introduction: Oral cancers account for $3 \%$ of total malignancies. A research was conducted to find the incidence, age, and sex distribution, clinical presentation, and the relationship between habits and various premalignant lesions of the oral cavity. Methods: It was a hospital-based observational and cross-sectional study, conducted in GSL Medical College, Rajamahendravaram from October 2015 to April 2017. Individuals aged $\geq 18$ years, with leukoplakia, erythroplakia, blanched mucosa with or without fibrous bands and /or trismus suggestive of oral submucous fibrosis, bilateral whitish lesions with a reticular pattern suggestive of lichen planus, and ulcer against sharp tooth denture suggestive of traumatic dental ulcers were taken. Individuals with frank oral malignancy, those with terminal diseases, those who did not submit informed consent were not considered. Results: The majority of patients (33.33\%) were aged between 51 - 60 years, belong (62.75\%) to lower socioeconomic status. Leukoplakia (64.7\%) was a common clinical presentation. Most (49.02\%) of the study patients presented with a burning sensation. When addictions were considered, $86.27 \%$ of patients were smokers, $23.53 \%$ were addicted to alcohol. Conclusion: Leukoplakia was the commonest (64.71\%) premalignant lesion, 51 - 60 years was the common age group. Premalignant lesions were most commonly seen among males, most of the study participants belong to low and middle socio-economic groups with a rural background. Diabetes mellitus was the most common comorbidity associated with premalignant lesions.

Keywords: Oral, Cancers, precancerous lesions, Habits, clinicopathological study

\section{Corresponding Author}

B Krishna Santosh, Associate Professor, Department of ENT, GSL Medical College, Rajahmundry, Andhra Pradesh, India.

Email: dryadlapalliajay@yahoo.co.in
How to Cite this Article

Yadlapalli AK, Santosh BK, Reddy DSK, Veeranjaneyulu $P$, Snehitha ML, Priyanka P. Relationship between habits and precancerous lesions of the oral cavity - a clinicopathological study. Trop J Ophthalmol Otolaryngol. 2021;6(1):0106.

Available From

https://opthalmology.medresearch.in/index.php/jooo

/article/view/160

\section{To Browse}

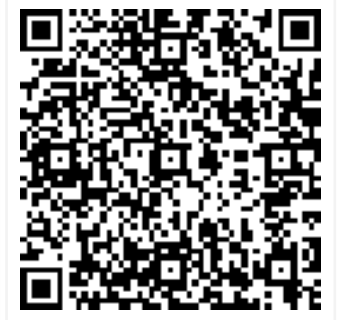

Manuscript Received 2020-08-24

Conflict of Interest No
Review Round 1 2020-09-04

Funding

$\mathrm{Nil}$

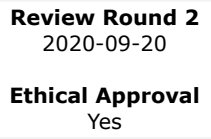

Ethical Approval Yes

Review Round 3

Plagiarism X-checker $6 \%$
Accepted 2020-12-29

Note

() 2021 by Ajay Kumar Yadlapalli, B Krishna Santosh, Dwarampudi S K Reddy, Panda Veeranjaneyulu, Maroju Lakshmi Snehitha, Pothula Priyanka and Published by Siddharth 'Health Research and Social Welfare Society. This is an Open Access article licensed under a Creative Commons Attribution 4.0 International License https://creativecommons.org/licenses/by/4.0/
unported [CC BY 4.0].

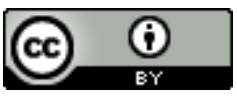




\section{Introduction}

Oral cavity cancers account for approximately $3 \%$ of total malignancies and a significant health problem, worldwide $[1,2]$. The majority of oral malignancies occur as squamous cell carcinoma and despite remarkable advances in treatment modalities, the 5 -year survival rate has not significantly improved over the past several decades, hovering at about $50 \%$ to $60 \%$ [3].

It is well accepted that many oral cancers (OCs) develop from premalignant lesions of the oral cavity $[4,5]$. A wide variety of conditions have been implicated in the development of OC, including leukoplakia, erythroplakia, oral lichen planus, oral submucous fibrosis, discoid lupus erythematosus, and hereditary disorders, such as dyskeratosis congenital and epidermolysisbullosa. The WHO classified these oral precancerous disorders into 2 general groups $[6,7]$. A precancerous lesion is a morphologically altered tissue in which oral cancer is likely to occur than its normal counterpart. A precancerous condition is a generalized state associated with a significantly increased risk of cancer.

Because of the incidence of precancerous conditions and lesions among the patient population attending ENT out Patient department with the diseases of the ear, nose, and throat, there is a need to follow these cases with the necessary clinical workup and histopathological examination. This may provide an opportunity to facilitate regular follow up of the patients with the early lesions and early initiation of definite treatment in established cases. Moreover, a study of the patient's environmental, social conditions, and personal habits is important for understanding the influence of these factors in the evolution of OC.

With this, the current research was conducted to find the incidence, age, and sex distribution, clinical presentation, and the relationship between habits and various premalignant lesions of the oral cavity.

\section{Methods}

Type of study: It was a hospital-based observational and cross-sectional study.

Study setting: This study was conducted in the department of ENT, GSL Medical College, Rajamahendravaram.
Study period: The study was conducted from October 2015 to April 2017.

Sample size: During the study period, the individuals with oral premalignant lesions, those who satisfied the study protocol were considered.

Inclusion criteria: The individuals aged $\geq 18$ years, with the following condition were included in the study. White patch in the oral cavity suggestive of leukoplakia, red plaque in the oral cavity suggestive of erythroplakia, blanched mucosa with or without fibrous bands and /or trismus suggestive of oral submucous fibrosis, bilateral whitish lesions with a reticular pattern suggestive of lichen planus and ulcer against sharp tooth denture suggestive of traumatic dental ulcers

Exclusion criteria: Individuals with frank oral malignancy, those with terminal diseases, those who did not submit informed consent, and noncooperative individuals were not considered.

Ethical approval: The study protocol was approved by the institutional ethical committee.

Those individuals visited the outpatient and or inpatient with various oral premalignant lesions such as leukoplakia, erythroplakia, erythroleukoplakia, oral submucous fibrosis, and lichen planus during the study period were taken up for study with the help of relevant history and thorough clinical examination.

Statistical analysis: Statistical analysis was performed using SPSS software version 20.0 and MS Excel-2007. Descriptive statistical data such as mean, standard deviation, and percentages were considered in this research.

\section{Results}

Table 1: Age-wise distribution of the study participants

\begin{tabular}{|l|l|l|}
\hline \multicolumn{1}{|c|}{ Age } & \multicolumn{1}{c|}{ Number } & \multicolumn{1}{c|}{ Percentage } \\
\hline $21-30$ & 1 & 1.96 \\
\hline $31-40$ & 10 & 19.61 \\
\hline $41-50$ & 11 & 21.57 \\
\hline $51-60$ & 17 & 33.33 \\
\hline $61-70$ & 12 & 23.53 \\
\hline Total & 51 & 100 \\
\hline
\end{tabular}

In this study total, 51 members were recruited. The majority of patients (33.33\%) were aged between 51-60 years, followed by $23.53 \%$ between $61-70$ years, $21.57 \%$ between $41-50$ years, 
$19.61 \%$ between $31-40$ years, and $1.96 \%$ between 21-30 years. Age was ranged from 24 to 70 years (Table 1). Out of the 51 study participants, 33 $(64.71 \%)$ were male and 18 (35.29\%) were female. The male-female ratio of the study team was 1.83 .

The majority of patients $(62.75 \%)$ belong to lower socioeconomic status, $31.37 \%$ belong to middle and $5.88 \%$ belong to upper socioeconomic status (Table 2 ). Areas wise, $80.39 \%$ (41) of study members belonged to rural and the remaining were urban population.

Table-2: Socioeconomic status of the study participants.

\begin{tabular}{|l|l|l|}
\hline \multicolumn{1}{|c|}{ Socioeconomic status } & Number & Percentage \\
\hline Lower & 32 & 62.75 \\
\hline Middle & 16 & 31.37 \\
\hline Upper & 3 & 5.88 \\
\hline Total & 51 & 100 \\
\hline
\end{tabular}

Leukoplakia was seen in 33 (64.71\%), erythroplakia in $10(19.61 \%)$, erythroleukoplakia in $4(7.84 \%)$, oral lichen planus in $3(5.88 \%)$, and oral submucous fibrosis was diagnosed in 1 (1.96\%). In this study group, leukoplakia is the most common lesion found followed by erythroplakia while oral submucous fibrosis is the least common (Table 3).

Table-3: Incidence of various premalignant lesions of the oral cavity among the study group.

\begin{tabular}{|l|l|l|}
\hline \multicolumn{1}{|c|}{ Premalignant lesion } & Number & \multicolumn{1}{c|}{ Percentage } \\
\hline Leukoplakia & 33 & $64.71 \%$ \\
\hline Erythroplakia & 10 & $19.61 \%$ \\
\hline Erythroleukoplakia & 4 & $7.84 \%$ \\
\hline Oral lichen planus & 3 & $5.88 \%$ \\
\hline Oral submucous fibrosis & 1 & $1.96 \%$ \\
\hline
\end{tabular}

In this study, $49.02 \%$ of patients presented with a burning sensation, $19.61 \%$ of patients presented with a white patch, $7.84 \%$ presented with a red patch, 3.92\% presented with decreased mouth opening. $25.49 \%$ of the patients were presented with asymptomatic or other symptoms (Table 4). When food habits were considered, 31 patients $(60.78 \%)$ consume spicy foods.

Table-4: Presenting complaints of patients in the study group.

\begin{tabular}{|l|l|l|}
\hline \multicolumn{1}{|c|}{ Symptoms } & Number & Percentage \\
\hline Burning sensation & 25 & 49 \\
\hline White patch & 10 & 19.6 \\
\hline Red patch & 4 & 7.8 \\
\hline Decreased mouth opening & 2 & 3.9 \\
\hline
\end{tabular}

\begin{tabular}{|l|l|l|}
\hline Asymptomatic & 13 & 25.4 \\
\hline
\end{tabular}

When addictions were considered, $86.27 \%$ of patients were smokers, $23.53 \%$ were addicted to alcohol, $19.61 \%$ were habituated to reverse smoking, $5.88 \%$ to gutkha, $1.96 \%$ to the pan. $9.8 \%$ of the study group was not having any habituations (Table 5). Fourteen (27.45\%) members were diabetic and 17 (33.33\%) were hypertensive.

Table-5: Habits and addictions in the study group.

\begin{tabular}{|l|l|l|}
\hline \multicolumn{1}{|c|}{ Habits } & \multicolumn{1}{c|}{ Number } & \multicolumn{1}{c|}{ Percentage } \\
\hline Smoking & 44 & 86.27 \\
\hline Reverse Smoking & 10 & 19.61 \\
\hline Alcohol Intake & 12 & 23.53 \\
\hline Gutkha & 3 & 5.88 \\
\hline Paan & 1 & 1.96 \\
\hline None & 5 & 9.80 \\
\hline
\end{tabular}

Among the study members, the hard palate was involved in $60.78 \%$, buccal mucosa was involved in $41.18 \%$ patients, the floor of the mouth in $5.88 \%$, tongue in $3.92 \%$, soft palate and retromolar trigone in $1.96 \%$ each, respectively (Table 6 ).

Table-6: Sites of predilection among the study participants.

\begin{tabular}{|l|l|l|}
\hline \multicolumn{1}{|c|}{ Area involved } & Number & \multicolumn{1}{c|}{ Percentage } \\
\hline Hard palate & 31 & 60.78 \\
\hline Buccal mucosa & 21 & 41.18 \\
\hline Floor of mouth & 3 & 5.88 \\
\hline Tongue & 2 & 3.92 \\
\hline Soft palate & 1 & 1.96 \\
\hline Retromolar trigone & 1 & 1.96 \\
\hline
\end{tabular}

\section{Discussion}

$\mathrm{OC}$ is a serious and growing problem in many parts of the globe. Oral and pharyngeal cancer grouped forms the sixth most common cancer in the world [8]. OC is sometimes preceded by clinically visible lesions that are noncancerous, to begin with, and which have therefore been termed precancerous.

Tobacco has been considered as a major etiological factor in the development of oral potentially malignant disorders $[9,10]$. A variety of oral potentially malignant disorders have been reported in the literature with the consumption of tobacco.

In Asians, oral potentially malignant disorders are known to be associated with cigarette smoking, excess alcohol consumption, and areca quid chewing [11]. 
In this study, leukoplakia was seen maximum (64.71\%), followed by erythroplakia (19.61\%). Isaäc van der Waal et al [12] also reported that leukoplakia is the most common potentially malignant disorder of the oral mucosa. The prevalence was approximately $1 \%$ while the annual malignant transformation ranges between 2 to $3 \%$. Cessation of smoking habits may result in regression or even disappearance of the leukoplakia and diminish the risk of cancer development either at the site of the leukoplakia or elsewhere in the mouth or the upper aerodigestive tract. Sunil Vitthal Rao et al [13] mentioned that $68.41 \%$ of cases were leukoplakia followed by oral lichen planus (13.16\%) oral submucous fibrosis (7.9\%). According to Buoquot et al [14] leukoplakia is the most common cause. In another recent study by Anna Starzyńska et al [15] leukoplakia was reported in $79.69 \%$ of study members.

Age-wise, the majority (33.33\%) of the study participants were aged 51-60 years followed by the $61-70$ (, 23.53\%) group. According to Sunil Vitthalrao Jagtap et al [13], 50-59 years is the common age group. Whereas common age was reported to be 50 - 70 years according to Anna Starzyńska et al [15], According to previous studies, cases with multiple oral premalignant lesions were more likely to be in the 45-54 year age group. In this study, the incidence is more in the age group of 51-60 years which correlates with the results of the above-mentioned studies [16].

In this study, 33 were males and 18 were females and gender was found to be significantly associated with the development of oral potentially malignant disorders with males being at higher risk to develop oral potentially malignant disorders. In another study, $65.79 \%$ were male and $34.21 \%$ were female patients, the ratio was 1.9 [17]. Male female ratio was mentioned to be 1.6 in Owais Gowhar et al [18], the risk of malignant transformation among male with chewing tobacco or smoking in some countries such as India, or older age and/or being a non-smoking female in other countries. Similar findings were reported by Prashant B. Patil et al [19].

The majority of patients $(62.75 \%)$ study members belonged to lower socioeconomic status, followed by middle $(31.37 \%)$ and upper $(5.88 \%)$ socioeconomic status. According to Sandeep Kumar et al. [20] larger proportion of the study, population belonged to the lower class (40.5\%) followed by the middle class $(32.5 \%)$.
Hard palate involvement was seen in $60.78 \%$, buccal mucosa involvement in $41.18 \%$. According to Anna Starzyńska et al. [15], the most common site involved was buccal mucosa (52.2\%). Whereas buccal mucosa involvement was $55.26 \%$ in a study by Sunil Vitthalrao Jagtap et al [13].

A correlative histopathological study was made of 6 patients with palatal carcinomata and 342 patients with palatal lesions (primarily leukoplakias) associated with reverse smoking by Fali S. Mehta et al [21], according to this study a very large number of palatal lesions, characterized by hyperkeratinization, were associated with the habit of reverse smoking, i.e. keeping the burning end inside the mouth.

In this study, $27.45 \%$ of patients were diabetic and $33.33 \%$ were hypertensive. According to the study by Sandeep Kumar et al [20] diabetic patients (24.6\%) and underweight individuals (20.1\%) showed a higher prevalence of oral potentially malignant disorders. Anna Starzyńska et al [15] did a study on oral premalignant lesions and concluded that most of the patients were 50-70 years and the most common coexisting disease was diabetes.

In this study, the cases with oral lichen planus were with normal habits except for one case with the habit of smoking. This correlates with the study by Vincent SD et al [22] on oral lichen planus in which no addictions were found in cases of oral lichen planus. Lichen planus seems to have an idiopathic or autoimmune etiology.

\section{Limitations}

Small sample size is the major limitation of this research.

\section{Conclusion}

In this study, leukoplakia was the commonest (64.71\%) premalignant lesion, 51-60 years was the common age group. Premalignant lesions were most commonly seen among males, most of the study participants belong to low and middle socioeconomic groups with a rural background.

\section{What does the study add to the existing knowledge?}

Diabetes mellitus was the most common comorbidity associated with premalignant lesions. 


\section{Author's contribution}

\section{Dr. Ajay Kumar Yadlapalli: Concept}

Dr. B Krishna Santosh: Study design

Dr. Dwarampudi S K Reddy: Manuscript preparation

Dr. Panda Veeranjaneyulu: Data analysis

\author{
Dr. Maroju Lakshmi Snehitha: Manuscript \\ preparation
}

Dr. Pothula Priyanka: Data analysis

\section{Reference}

01. Kademani D. Oral cancer. Mayo Clin Proc. 2007;82(7)878-887.

doi: $10.4065 / 82.7 .878$ [Crossref]

02. Silverman S Jr. Demographics and occurrence of oral and pharyngeal cancers, The outcome, the trends, the challenge. J Am Dent Assoc. $2001 ; 132 ; 7$ S-11S.

doi: 10.14219/jada.archive.2001.0382 [Crossref]

03. Ries LAG, Melbert D, Krapcho M. SEER cancer statistics review, 1975-2005. Bethesda (MD)National Cancer Institute. 2008.

Available at: [Article] [Crossref]

04. Silverman S Jr, Gorsky M, Lozada F. Oral leukoplakia and malignant transformation- a follow-up study of 257 patients. Cancer. $1984 ; 53(3) 563-568$.

doi: $10.1002 / 1097-0142(19840201) 53: 3<563$ : :aidcncr2820530332>3.0.co;2-f [Crossref]

05. Sol Silverman Jr, DDS, Richard D Rozen, DDS. Observations on the clinical characteristics and natural history of leukoplakia. J Am Dent Assoc. $1968 ; 76(4) 772-777$.

doi: 10.14219/jada.archive.1968.0141 [Crossref]

06. Pindborg J], Reichart P, Smith CJ, van der Waal I (1997). World Health Organization- histological typing of cancer and precancer of the oral mucosa. Berlin- Springer-Verlag.

[Crossref]
07. Axéll T, Pindborg JJ, Smith CJ, van der Waal I. Oral white lesions with special reference to precancerous and tobacco- related lesionsconclusions of an international symposium held in Uppsala, Sweden, May 18-21 1994, International Collaborative Group on Oral White Lesions. J Oral Pathol Med. 1996;25(2)49-54. doi: 10.1111/j.1600-0714.1996.tb00191.x [Crossref]

08. Warnakulasuriya S. Global epidemiology of oral and oropharyngeal cancer. Oral Oncol. 2009;45(4-5)309-316.

doi: $10.1016 /$ j.oraloncology.2008.06.002 [Crossref]

09. Thomas G, Hashibe M, Jacob BJ, Ramadas K, Mathew B, Sankaranarayanan R, Zhang ZF. Risk factors for multiple oral premalignant lesions. Int J Cancer. 2003;107(2)285-291. doi: $10.1002 /$ ijc.11383 [Crossref]

10. Hashibe M, Mathew B, Kuruvilla B, Thomas G, Sankaranarayanan R, Parkin DM, et al. Chewing tobacco, alcohol, and the risk of erythroplakia. Cancer Epidemiol Biomarkers Prev. 2000;9(7)639-645.

[Crossref]

11. $\mathrm{CH}$ Chung, YH Yang, TY Wang, TY Shieh, S Warnakulasuriya. Oral precancerous disorders associated with areca quid chewing, smoking, and alcohol drinking in southern Taiwan. J Oral Path and Med. 2005;34(8)460-466.

doi: j.1600-0714.2005.00332.x [Crossref]

12. Isaäc van der Waal. Oral potentially malignant disorders: Is malignant transformation predictable and preventable. Med Oral Patol Oral Cir Bucal. 2014;19(4)e386-e390. doi: 10.4317/medoral.20205 [Crossref]

13. Jagtap SV, Warhate $P$, Saini N, Jagtap SS, Chougule PG. Oral premalignant lesions: a clinicopathological study. Int Sur J. 2017;4(10)3477-3481.

doi: 10.18203/2349-2902.isj20174520 [Crossref]

14. Bouquot, JE. Reviewing oral leukoplakia-clinical concepts for the 1990s. J Amer Dent Assoc. $1991 ; 122(6) 80-82$.

doi: $10.1016 / \mathrm{s} 0002-8177(91) 26024-9$ [Crossref] 
15. Starzyńska A, Pawłowska A, Renkielska D, Michajłowski I, Sobjanek M, Błażewicz I. Oral premalignant lesions- epidemiological and clinical analysis in the northern Polish population. Postepy Dermatol Alergol. 2014;31(6)341-350.

doi: 10.5114/pdia.2014.40932 [Crossref]

16. Chung $\mathrm{CH}$, Yang $\mathrm{YH}$, Wang TY, Shieh TY, Warnakulasuriya S. Oral precancerous disorders associated with areca quid chewing, smoking, and alcohol drinking in southern Taiwan. J Oral Pathol Med. 2005;34(8)460-466.

doi: $10.1111 /$ j.1600-0714.2005.00332.x [Crossref]

17. Silverman S, Gorsky M, Lozada F. Oral leukoplakia and malignant transformation, A follow-up study of 257 patients. Cancer. $1984 ; 53(3) 563-568$.

doi: $10.1002 / 1097-0142(19840201) 53: 3<563$ : :aidcncr2820530332>3.0.co;2-f [Crossref]

18. Gowhar O, Ain TS, Singh NN, Sultan S. Prevalence of oral premalignant and malignant lesions in moradabad, India - A Retrospective Study. Int J Cont Med Res. 2016;3(7)20792081.

[Crossref]
19. Patil PB, Bathi B, Chaudhari S. Prevalence of oral mucosal lesions in dental patients with tobacco smoking, chewing, and mixed habits- A cross-sectional study in South India. J Fam and Com Med. 2013;20(2)130-135. doi: $10.4103 / 2230-8229.114777$ [Crossref]

20. Kumar S, Debnath $N$, Ismail MB, Kumar $A$, Kumar A, Badiyani BK. Prevalence and Risk Factors for Oral Potentially Malignant Disorders in Indian Population. Adv Prev Med. 2015; $2015 ; 208519$.

doi: $10.1155 / 2015 / 208519$ [Crossref]

21. Mehta FS, Sahiar BE, Daftary DK, Gupta PC, Pindborg J]. A correlative histocytological study of carcinoma and epithelial atypia of the palate among Indian reverse smokers. $\mathrm{Br} \mathrm{J}$ Cancer. $1972 ; 26(3) 230-233$.

doi: $10.1038 /$ bjc.1972.31 [Crossref]

22. Vincent SD, Fotos PG, Baker KA, Williams TP. Oral lichen planus- the clinical, historical, and therapeutic features of 100 cases. Oral Surg Oral Med Oral Pathol Oral Radiol Endod. 1990;70(2)165-171.

doi: 10.1016/0030-4220(90)90112-6.z [Crossref] 